1 Recovery of hand function after stroke: separable systems for finger strength and

control

5 Jing $\mathrm{Xu}^{1 *}$, Naveed $\mathrm{Ejaz}^{2,3 *}$, Benjamin Hertler ${ }^{4}$, Meret Branscheidt ${ }^{4,7}$, Mario Widmer ${ }^{4}$,

6 Andreia V. Faria ${ }^{5}$, Michelle Harran ${ }^{6}$, Juan C. Cortes ${ }^{6}$, Nathan Kim ${ }^{1}$, Pablo A. Celnik ${ }^{7}$,

7 Tomoko Kitago $^{6}$, Andreas R. Luft ${ }^{4,8}$, John W. Krakauer ${ }^{1}$, Jörn Diedrichsen ${ }^{2,3}$

9 1. Department of Neurology and Neurosciences, Johns Hopkins University, Baltimore,

$10 \mathrm{MD}, \mathrm{USA}$

11 2. Institute of Cognitive Neuroscience, University College London, London, UK

12 3. Brain Mind Institute, University of Western Ontario, London, ON, Canada

13 4. Division of Vascular Neurology and Rehabilitation, Department of Neurology,

14 University Hospital and University of Zürich, Zürich, Switzerland

15 5. Department of Radiology, Johns Hopkins University, Baltimore, MD, USA

16 6. Department of Neurology, Columbia University, New York, NY, USA

17 7. Department of Physical Medicine and Rehabilitation, Johns Hopkins University,

18 Baltimore, MD, USA

19 8. Cereneo Center for Neurology and Rehabilitation, Vitznau, Switzerland

$20 *$ These authors contributed equally to this work

\title{
22 Contact information
}

23 Jing $\mathrm{Xu}$ 
24 Department of Neurology

25 School of Medicine

26 Johns Hopkins University

27 Pathology 2-210

28600 N. Wolfe St.

29 Baltimore, MD 21287 USA

30 Email: jing.xu@jhmi.edu

\section{Number of figures: 6}

\section{Number of tables: 2}

\section{Number of words:}

35 Abstract: 197 (limit 250)

36 Introduction: 603 (limit 650)

37 Discussion: 1360 (limit 1500)

\section{Acknowledgement}

40 We thank Adrian Haith and Martin Lindquist for helpful discussions about data analysis.

41 This main study was supported by James S. McDonnell Foundation JMSF 220020220.

42 Additional support came from a Scholar Award from the James S. McDonnell

43 Foundation and a Grant from the Wellcome Trust (094874/Z/10/Z) to Jörn Diedrichsen.

44 Andreas R. Luft is supported by the P\&K Pühringer Foundation. 


\section{Abstract}

47 Loss of hand function after stroke is a major cause of long-term disability. Hand function

48 can be partitioned into strength and independent control of fingers (individuation). Here

49 we developed a novel paradigm, which independently quantifies these two aspects of

50 hand function, to track hand recovery in 54 patients with hemiparesis over the first year

51 after their stroke. Most recovery of both strength and individuation occurred in the first

52 three months after stroke. Improvement in strength and individuation were tightly

53 correlated up to a strength level of approximately $60 \%$ of the unaffected side. Beyond

54 this threshold, further gains in strength were not accompanied by improvements in

55 individuation. Any observed improvements in individuation beyond the $60 \%$ threshold

56 were attributable instead to a second independent stable factor. Lesion analysis revealed

57 that damage to the hand area in motor cortex and the corticospinal tract (CST) correlated

58 more with individuation than with strength. CST involvement correlated with

59 individuation even after factoring out the strength-individuation correlation. The most

60 parsimonious explanation for these behavioral and lesion-based findings is that most

61 strength recovery, along with some individuation, can be attributed to descending

62 systems other than the CST, whereas further recovery of individuation is CST dependent.

\section{Keywords:}

65 Finger individuation, strength, stroke, motor recovery, plasticity 


\section{Introduction}

Human hand function comprises at least two complementary aspects: strength as

69 manifest in a power grip, and control of individual finger movements as in piano playing.

70 The most common observation after stroke is that both are impaired (Kamper and Rymer,

71 2001; Lang and Schieber, 2003). Weakness presents as difficulties in voluntarily opening

72 of the hand, extending the wrist and fingers against resistance, and producing a strong

73 grip (Colebatch and Gandevia, 1989; Kamper et al., 2003). Loss of finger control

74 manifests as inability to either move a single finger while keeping the others immobile, or

75 to make complex hand gestures, both of which impair the ability to perform tasks such as

76 typing or buttoning a shirt (Kamper and Rymer, 2001; Li et al., 2003; Lang and Schieber,

77 2004). When strength does recover after stroke, control often remains impaired, causing

78 lasting disability (Heller et al., 1987; Sunderland et al., 1989). However, the relationship

79 between strength and control after stroke remains poorly understood. Separating the

80 effect of stroke on finger strength versus control is a challenge given that most current

81 clinical measurements conflate weakness with deficits in control. In the current study we

82 therefore sought to develop a new paradigm that could measure these two aspects of hand

83 function separately, and to investigate the relationship between strength and control over

84 the time course of hand recovery after stroke. We were specifically interested to test

85 whether these two components recover in a lawful relationship with each other, or

86 whether they recover independently.

87 Existing behavioral tasks used to assess hand function after stroke, such as the

88 Fugl-Meyer Assessment (FMA) (Fugl-Meyer et al., 1975), the Nine-Hole Peg Task

89 (9NPT) (Sharpless, 1982), and the Action Reach Arm Test (ARAT) (Lyden and Lau, 
90 1991), are not designed to separate deficits in strength and control. To isolate these two

91 aspects of hand function it is necessary to remove any obligatory relationship between

92 them (Reinkensmeyer et al., 1992), i.e. derive a control measure that is independent of

93 strength. Intuitively, a rock climber may have stronger fingers than a pianist, but not

94 necessarily superior control of individual fingers.

95 Schieber (1991) devised an individuation task that requires participants to move

96 individual fingers while keeping the non-moving ones stationary. Movements of the

97 passive fingers were used as a measure of loss of control. This paradigm however does

98 not directly track the force relationship between active and passive fingers. In the

99 paradigm used here, we first measured the maximum voluntary contraction force (MVF)

100 that a participant could produce with each finger. We then asked participants to produce

101 isometric forces over four sub-maximal levels with each finger, while keeping the passive

102 fingers immobile. Even controls show involuntary force production (enslaving) on the

103 passive fingers, which increases with the required active force level (Li et al., 1998;

104 Zatsiorsky et al., 2000). The slope of the function of passive finger enslaving on active

105 force thus provides a measure of individuation that is independent of strength.

106 Using this paradigm we tracked the recovery of hand strength and finger

107 individuation in patients over a one-year period after stroke. One possibility is that

108 strength and control recover independently. For example, a patient may remain quite

109 weak but have good recovery of individuation, or a patient may recover a significant

110 amount of grip strength but fail to individuate the digits. Alternatively, recovery may be

111 such that when strength recovers so does individuation, because either they share a

112 common neural substrate or repair processes are proceeding in parallel in separate neural 
113 substrates. Finally, lesion analysis allowed us to investigate whether there is any

114 identifiable anatomical basis for any observed dissociation between strength and control

115 deficits.

116

Materials and Methods

118 Participants

119 Fifty-four patients with first-time ischemic stroke and hemiparesis (34 male, 20

120 female; mean age $57.4 \pm 14.9$ years) were recruited from three centers: The Johns Hopkins

121 Hospital and Affiliates, Columbia University Medical Center, and The University

122 Hospital of Zurich and Cereneo Center for Neurology and Rehabilitation. According to

123 the Edinburgh Handedness Inventory (Oldfield, 1971), Forty-four patients were right-

124 and 10 were left-handed. All patients met the following inclusion criteria: 1) First-ever

125 clinical ischemic stroke with a positive DWI lesion within the previous 2 weeks; 2) One-

126 sided upper extremity weakness $(\mathrm{MRC}<5)$; 3) Ability to give informed consent and

127 understand the tasks involved. We excluded patients with one or more of the following

128 criteria: initial UE FMA > 63/66, age under 21 years, hemorrhagic stroke, space-

129 occupying hemorrhagic transformation, bihemispheric stroke, traumatic brain injury,

130 encephalopathy due to major non-stroke medical illness, global inattention, large visual

131 field cut (greater than a quadrantanopia), receptive aphasia (inability to follow 3-step

132 commands), inability to give informed consent, major neurological or psychiatric illness

133 that could confound performance/recovery, or a physical or other neurological condition

134 that would interfere with arm, wrist, or hand function recovery. Due to the exclusion of

135 aphasic patients, the sample had a bias towards right-sided infarcts (17 left-sided, 37 
136 right-sided; for detailed patient characteristics, see Table 1). The lesion distribution is

137 shown in Fig. 5A.

138 We also recruited 14 age-matched healthy control participants (10 male, 4

139 female; mean age $64 \pm 8.2$ years; all right-handed) at the three centers. There was no age

140 difference between the patient and control samples (two-samples t-test $t(65)=1.60, p=$

1410.11 ), nor did the ratio of gender and handedness in the two groups differ (Fisher's exact

142 test yielded results of $p=0.11$ and 0.75 , respectively). The healthy controls did not have

143 any neurological disorder or physical deficit involving the upper limbs. All participants

144 signed a written consent, and all procedures were approved by Institutional Research

145 Board at each study center.

Assessment of finger maximum voluntary contraction and of individuation

148 To achieve good characterization of hand function recovery, the study design

149 required patient testing at the following five time points post-stroke: within the first 2

150 weeks (W1, 10 \pm 4 days), at 4-6 weeks (W4, 37 \pm 8 days), 12-14 weeks (W12, 95 \pm 10 days),

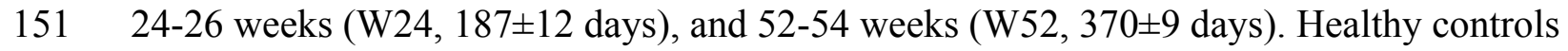

152 were tested at comparable intervals.

153 At each of the five visits, hand function was tested using an ergonomic device that

154 measures isometric forces produced by each finger (Fig. 1A). The hand-shaped keyboard

155 was comprised of ten keys. Force transducers (FSG-15N1A, Honeywell ${ }^{\circledR}$; dynamic range

$156-0-50 \mathrm{~N}$ ) measured the force exerted by each finger with a sampling rate of $200 \mathrm{~Hz}$. The

157 data were digitized using National Instrument USB-621x devices interfacing with

158 MATLAB (The MathWorks, Inc., Natick, MA) Data Acquisition Toolbox. Visual stimuli 
159 of the task were presented on the computer monitor, run by custom-written software

160 using the Psychophysics Toolbox (Psychotoolbox) in MATLAB environment (Brainard,

161 1997).

162 Participants were seated in a comfortable chair, facing the computer monitor.

163 During the entire procedure, participants rested their two hands on the keyboards with

164 each finger on top of a key, their wrists were strapped and fixed on a wrist-rest, and their

165 forearms extended and supported by foam arm rests. Throughout the experiment, ten

166 vertical gray bars representing the ten digits appeared on top of the screen, and another

167 ten vertical bars below them instructed the amount of force to be exerted; the required

168 force level for each finger in each trial was indicated by the height of green filling the

169 vertical gray bar (Fig. 1B). Participants could monitor the force exerted by all ten digits

170 in real time by the heights of ten small white horizontal lines moving along the vertical

171 force bars.

172 Two separate aspects of finger function were tested: maximal voluntary

173 contraction force (MVF) and individuation. During each MVF trial, participants were

174 asked to depress one finger at a time with its maximum strength, and maintain the force

175 level for two seconds. The participants could press with the other fingers as much as they

176 wanted as long as maximal force on the instructed finger was achieved. To signal the

177 start, one force bar corresponding to the instructed finger turned to green. MVF was

178 measured twice per digit.

179 In the individuation task, participants had to press each individual finger at a sub-

180 MVF level of force, while at the same time keeping their other fingers immobile on the

181 keys. Four target force levels were tested for each digit: $20 \%, 40 \%, 60 \%$, and $80 \%$ of 
182 MVF, and each level was repeated 4 times. On each trial, a section of a force bar

183 corresponding to the finger to be depressed turned to green, with the height of the middle

184 black line representing the target force level and the green region around the middle line

185 representing the $25 \%$ upper and lower bounds around the target force level (Fig. 1B). The

186 participants were asked to bring the corresponding white line up to the force target line,

187 and maintain the force level for $0.5 \mathrm{sec}$. If no response passing the force threshold of 2.5

$188 \mathrm{~N}$ was detected within two seconds, the trial was terminated.

\section{Data analysis}

Strength Index. The 95th percentile of the force traces produced across all the

195 sampled force data points during the finger depressing period in each trial was calculated,

196 and then averaged across the two MVF trials to obtain a measure of MVF for each digit.

197 If the force achieved on one of the two trials was below $60 \%$ of the force produced on the

198 other trial, only the larger force was taken as MVF measure $(6.5 \%$ of the trials were

199 excluded). The overall strength of the hand was then calculated by averaging across all

200 five digits. To account for the large inter-subject variability in premorbid strength, all

201 MVF values were normalized by MVF of the non-paretic hand at W52; estimated using a

202 mixed-effects model (see below). This normalization provided a Strength Index, with a

203 value close to 1 implying full recovery. For control participants, one of the hands was

204 randomly assigned to take the role as the "non-paretic" hand for normalization purposes. 
205 To account for possible laterality effects, the assignment followed the ratio of dominant

206 to non-dominant hands found in the patients $(\sim 10: 4)$.

207 Individuation Index. If individuation was perfect, a participant should be able to

208 press the instructed finger without any force being exerted by the passive fingers. For

209 each time bin $t(5 \mathrm{~ms})$ in a single trial, we calculated the enslaved deviation of the force of

210 each passive finger $\left(F_{t, j}\right)$ from baseline force $\left(B F_{j}\right)$, which was assessed at the beginning

211 of the trial when a go cue was presented. This deviation was averaged over all bins $(T)$ in

212 the force trace from the go cue to the end of the trial:

$$
\text { meanDevP }=\frac{1}{T} \sum_{t=0}^{T} \sqrt{\sum_{j=\text { passive }}\left(F_{t, j}-B F_{j}\right)^{2}}
$$

214 where the index $j$ denotes the $j$ th passive finger. A higher mean deviation indicates more

215 enslaving of the passive finger.

216 For a measure of individuation ability, it is necessary to account for the

217 relationship between the force deviations of the passive fingers to the force produced by

218 the active finger. Consistent with previous reports (Li et al., 1998), we observed that

219 enslaving of passive fingers increases with higher active force (Fig. 1E). The relationship

220 between the two variables was close to linear. Thus a good measure of individuation is

221 how much the mean deviation in passive fingers increases for each $N$ of force produced

222 by the active finger. The ratio of these two variables can be reliably estimated by fitting a

223 regression line without an intercept. To reduce the influence of outliers, we used robust

224 regression (Holland and Welsch, 1977). The slope of the regression line reflects

225 individuation ability: The smaller the slope, the better the individuation ability, with the

226 best case being 0 , which means keeping the passive fingers perfectly immobile at any

227 active force level. Because the regression slope is bounded by zero (as mean deviation is 
228 positive), its distribution is positively skewed. To allow for the use of parametric

229 statistics the slope was log-transformed. The sign of this value was inverted, so that

230 higher values would correspond to better function. The negative log slope was calculated

231 separately for each active finger and then averaged across fingers, giving the

232 Individuation Index for the hand. As was done for the Strength Index, the Individuation

233 Index was normalized by each participant's "non-paretic" (randomly assigned for healthy

234 controls) hand's W52 value as estimated by mixed-effect model to provide the final

235 Individuation Index for each hand.

236 Reliability measures for Strength and Individuation. To determine the reliability

237 of the Strength and Individuation Indices, split-half reliabilities for both measures were

238 calculated. For the Strength Index, we used one MVF trial per digit in each split. We then

239 calculated the (normalized) Strength Index on each half of the data independently in the

240 same way as for the full data set. The correlation between the two halves across all

241 available sessions and patients was then used as a measure of split-half reliability.

242 For the Individuation Index, data from each finger was split such that two trials

243 per force level were assigned to each split. The slope of the regression line and

244 Individuation Index was then calculated separately for each split, and normalized in the

245 same way as MVF. We repeated the split multiple times, each time assigning trials at

246 random and then averaging the split-half correlations from all splits for more reliable

247 results.

248 Split-half correlation will underestimate reliability because the variability in each

249 half will be higher than the variability when using all the data (Guttman, 1945). The

250 estimate was therefore corrected using the formula 


$$
r_{f u l l}=\frac{2 r_{p}}{r_{p}+1}
$$

252 where $r_{p}$ is the correlation between the two splits.

253 Stability analysis. To assess whether the relative deficits in strength and

254 individuation remained stable across different testing time points, or whether there was

255 meaningful biological change, we calculated the correlation of each measure across

256 neighboring testing time points. One caution when interpreting these correlations is that

257 the correlation between two repeated measures will always be smaller than 1 even if the

258 underlying factor did not change. This is because both measures contain some

259 measurement noise. To account for this effect, we used the reliability $\left(r_{f u l l}\right)$ of the measure

260 at each time point to compute a noise ceiling, which indicates how much two repeated

261 noisy measurements should correlate with each other if the underlying variable were

262 perfectly stable:

$$
r_{\text {noise ceiling }}=\sqrt{r 1_{\text {full }} * r 2_{\text {full }}} \text {. }
$$

265 using custom-written MATLAB and R (R Core Team, 2012) routines. The analysis

266 focused on the Strength and Individuation Indices, but was also performed on standard

267 clinical assessments, FMA, ARAT, and Dynamometry strength measures.

268 The requirement for 5 post-stroke time-points was ambitious, with the

269 consequence of some missing sessions. A total of 21 patients completed all five time-

270 points; on average each patient completed 3.6 sessions; thus a total of $75 \%$ of the possible

271 sessions were acquired. To optimally use all the measured data, we employed linear

272 mixed-effect models. The model specifies joint distributions for observed and missing 
273 observations - then the parameters of those distributions can be estimated by maximizing

274 the likelihood of the data under the model. There are several advantages to this approach.

275 First, all the available data can be used and there is no need to exclude any data.

276 Secondly, it avoids the statistical pitfalls inherent in "filling in" missing observations

277 with point estimates. Linear mixed-effect models implemented in the lme 4 package in $\mathrm{R}$

278 (Bates et al., 2014) were used to test the changes in these measures over time. Participant

279 was taken as a random factor. Time Point (five time points from W1-W52) and Hand

280 Condition (paretic, non-paretic, and control) were considered fixed factor. The model was

281 applied to control and patient data separately. Mixed-effect model estimation for group

282 summary statistics was implemented in MATLAB using the restricted maximum

283 likelihood method (Laird and Ware, 1982).

284 Modeling the time-invariant function. To test the hypothesis that there is time-

285 invariant relationship between strength and individuation, a two-segment piecewise linear

286 function was fitted. This function had four free parameters: the intercept, the location of

287 the inflection point, and the slope on each side of the inflection point. Let $x$ be the

288 predictor with two segments separated by a constant breakpoint $c, x_{1} \leq c$ and $x_{2} \geq c$. The

289 linear functions for each segment are

$$
\begin{aligned}
& y_{1 i}=b_{10}+b_{11} x_{1 i}+e_{1 i} \\
& y_{2 i}=b_{20}+b_{21} x_{2 i}+e_{2 i}
\end{aligned}
$$

291 The two pieces can be joined at the breakpoint constant $\mathrm{c}$ by setting $y_{1 i}=y_{2 i}$, yielding

$$
\begin{aligned}
& b_{20}=b_{10}+\left(b_{11}-b_{21}\right) c \\
& y_{2 i}=b_{10}+\left(b_{11}-b_{21}\right) c+b_{21} x_{2 i}+e_{2 i}
\end{aligned}
$$

293 Putting the two pieces together, we have the full model 


$$
y_{i}=a+b_{1} x_{i} \cdot I\left(x_{i} \leq c\right)+\left[\left(b_{1}-b_{2}\right) c+b_{2} x_{i}\right] \cdot I\left(x_{i} \geq c\right)+e_{i}
$$

296 where $I(\cdot)$ is an indicator variable, coded as 1's or 0's to indicate the condition satisfied.

298 obtained by using the non-linear optimization routine fminsearch in Matlab. Leave-one-

299 out cross-validation (Picard and Cook, 1984) was used to evaluate whether this function

300 changed systematically over time, or whether it was time-invariant. The time-invariant

301 model with fixed parameters across all time points was compared with a more complex

302 model that allowed free parameters for each time point. Cross validation provides an

303 unbiased estimate of a model's ability to predict new data and automatically penalizes

304 models that are too complex.

\section{Lesion Imaging and Quantification}

307 Imaging acquisition and lesion distribution. Images were acquired using 3T MRI

308 Phillips scanner and consisted of two DTI datasets (TR/TE=6600/70ms, EPI, 32 gradient

309 directions, $b=700 \mathrm{~s} / \mathrm{mm} 2)$, and an MPRAGE T1-WI (TR/TE=8/3.8ms) sequence. FOV,

310 matrix, number of slices, and slice thickness were $212 \times 212 \mathrm{~mm}, 96 \times 96$ (zero-filled to

$311256 \times 256), 60,2.2 \mathrm{~mm}$, respectively, for DTI; and 256×256mm, 256×256, 170, 1.2mm,

312 respectively, for T1-WI. The DTI were processed using DtiStudio (www.MRIStudio.org)

313 and the mean diffusion-weighted image (DWI) was calculated.

314 To define the boundary(s) of the acute stroke lesion(s) for each participant, a

315 threshold of $>30 \%$ intensity increase from the unaffected area in the first-time-point

316 diffusion-weighted image (DWI) extracted from DTI images was applied. A 
317 neuroradiologist (AVF), blind to the patients' clinical information, manually modified the

318 boundary to avoid false-positive and false-negative areas on RoiEditor

319 (www.MRIstudio.org). The definitions were double checked by a second rater (MB). The

320 averaged lesion distribution map across all patients in the current study is shown in Fig.

$3215 \mathrm{~A}$. For the seven patients who had no DTI in the acute phase, lesion definition was

322 performed on the clinical DWI, which has lower resolution ( $1 \mathrm{x} 1 \mathrm{~mm}$ in plane, $4-6 \mathrm{~mm}$

323 thickness). Analysis of white matter ROIs, including the CST, was not performed in

324 patients.

325 Region of interest definition and lesion quantification. The focus was on two

326 ROIs: 1) The cortical gray matter of the hand area in the motor cortex; 2) The entire CST

327 superior to pyramids, identified by probabilistic maps derived from tract tracing methods

328 (see below). The percentage volume affected in these regions was correlated with our

329 main outcome measures, the Strength and Individuation Indices.

330 To defined the CST, each image and respective lesion were mapped to a single

331 subject adult template, the JHU-MNI atlas (Mori et al., 2008; Oishi et al., 2008, 2009,

332 2010), using affine transformation followed by dual channel (both b0 and FA maps) large

333 deformation diffeomorphic metric mapping (LDDMM) (Ceritoglu et al., 2009). This

334 template has already been segmented into more than 200 regions of interest (ROIs), and

335 contains probabilistic maps of multiple tracts, including the CST (Zhang et al., 2010). To

336 ensure accurate mapping, we first used "artificial" images, in which the stroke area was

337 masked out and substituted by the normal images from the contralateral hemisphere. This

338 helped to minimize inaccuracies caused by the focal changes in intensity due to the

339 stroke. The white matter beneath the cortex was identified with a FA-threshold of 0.25. 
340 The segmentation defined in the template, as well as a probabilistic map of the CST, were

341 then "back-warped" by each subject's deformation field to generate individualized

342 parcellations.

343 A different approach was used to define an ROI that would encompass the hand

344 area of the primary motor cortex. The hand ROI was defined on the average

345 reconstruction of the cortical surface available in the Freesurfer software (Dale et al.,

346 1999), selecting Brodmann area (BA) 4 based on cytoarchitectonic maps (Fischl et al.,

347 2008). To restrict the ROI to the area of motor cortex involved in the control of the upper

348 limb, we only included the area $2.5 \mathrm{~cm}$ dorsal and ventral of the hand knob (Yousry et

$349 a l ., 1997)$. The defined ROI was then morphed into MNI space using the surfaces of the

350 age-matched controls. These ROIs were then brought to the JHU-MNI atlas (in which

351 each subject and respective stroke area were already mapped, as mentioned above) using

352 T1-based LDDMM to construct a probabilistic map of the hand area. The probabilistic

353 map was threshold of $70 \%$ to calculate percent-volume affected.

\section{$355 \quad$ Clinical assessments}

356 At each visit, all participants were also assessed with several clinical outcome

357 measures. Here we report data for FMA and ARAT. Grip strength was assessed with a

358 Jamar hydraulic hand dynamometer (Sammons Preston, Rolyan, Bolingbrook, IL, USA).

359 Strength in the first dorsal interosseous (FDI) and the flexor carpi radialis (FCR) muscles

360 was assessed using a hand-held dynamometer (Hoggan MiroFET2 Muscle Tester, Model

361 7477, Pro Med Products, Atlanta, GA, USA). 


\section{Results}

364 A total of 54 patients with acute stroke and 14 healthy controls underwent five

365 testing sessions over a one-year period. Data in the final analysis comprised a total of 251

366 sessions tested in 53 patients (one patient only completed two blocks of the task, and was

367 thus removed from further analysis) and 14 controls. Forty-one patients and twelve

368 controls completed $>=3$ sessions. The data were $75 \%$ complete, with $25 \%$ of the sessions

369 were missing or unusable. Non-tested sessions were treated as data missing at random

370 and all available data were used in the statistical analysis (see Materials and Methods).

\section{The Strength and Individuation Indices were reliable.}

373 Finger strength was assessed by measuring the maximum voluntary force (MVF)

374 for each finger separately and then averaged across all fingers for each hand. MVF for

375 healthy controls had an average value of $20.35 \mathrm{~N}(\mathrm{SD}=8.56)$ for the dominant hand, and

$37622.76 \mathrm{~N}(\mathrm{SD}=6.89)$ for the non-dominant hand. The normalized Strength Index for the

377 controls' dominant hand was $1.00(\mathrm{SD}=0.19)$, and non-dominant hand was $1.17(\mathrm{SD}=$

378 0.25). For patients, the mean for the non-paretic hand was $0.93(\mathrm{SD}=0.20)$, and for the

379 paretic hand it was $0.59(\mathrm{SD}=0.38)$. For the paretic hand, Strength Indices did not

380 correlate with age $(r=0.04, p=0.75)$, nor were they affected by gender $(t(51)=0.98, p=$

$3810.33)$ or handedness $(t(51)=0.10, p=0.92)$.

382 To assess individuation, we measured the amount of involuntary force changes

383 (enslaving) on the passive fingers for different levels of force production with the active

384 fingers. The amount of enslaving systematically increased at higher force levels (Fig.

385 1E). Loss of control at increasing force levels has been shown for the angular position of 
386 the fingers (Li et al., 1998) and the reaching radius of the arm after stroke (Sukal et al.,

387 2007; Ellis et al., 2009). To control for this relationship, we characterized the

388 Individuation Index as the slope of the function between active force and passive

389 enslaving. Lower values of Individuation Index indicate more impaired individuation.

390 Healthy, age-matched controls showed, on average, a normalized Individuation Index of

$3911.00(\mathrm{SD}=0.18)$. This refers to a slope of $0.087(\mathrm{SD}=0.046)$, meaning that for a finger

392 press of $10 \mathrm{~N}$ the mean deviation of the passive fingers was $0.69 \mathrm{~N}$. As was the case for

393 Strength, Individuation Indices in the paretic hand were not correlated with age $(r=0.16$,

$394 p=0.26)$, nor affected by gender $(t(51)=0.17, p=0.86)$ or handedness $(t(51)=0.34, p=$

395 0.74).

396 When introducing a new instrument, it is important to first establish its reliability,

397 i.e., the accuracy with which true differences between subjects and changes within

398 subject can be determined. We therefore split the data for each session in half, calculated

399 Strength and Individuation Indices on these two independent data sets, and correlated the

400 resultant scores across patients and sessions (see methods). The adjusted split-half

401 reliability across all patients and weeks for the Strength Index was $r_{\text {full }}=0.99$ and 0.94

402 for the paretic and non-paretic hands respectively, and $r_{\text {full }}=0.89$ for controls, which

403 indicates good reliability. The adjusted split-half reliability of the Individuation Index of

404 all patients was $r_{f u l l}=0.99$ and 0.93 for the paretic and non-paretic hands respectively,

405 and for controls was $r_{f u l l}=0.97$.

406 Consistent with our effort to construct an individuation measure that is

407 independent of strength, the overall correlation between Individuation and Strength in 
408 controls was very low for both controls $(r=-0.19, p=0.51)$, and for patients' non-paretic

409 hand $(r=0.17, p=0.21)$.

411 The Strength and Individuation indices correlated with standard clinical measures.

412 The Strength and Individuation Indices were compared with existing clinical measures:

413 the Fugl-Meyer (a measure of impairment) and ARAT (a measure of activity) Table 2

414 shows the correlations for all four measures obtained from the paretic hand across all

415 time points. Overall, all correlations were very high $\left(\max p=1.21 \times 10^{-26}\right)$, indicating that

416 all the measures could detect severity of the hand function deficit. The correlation in the

417 patients between the two clinical measures was 0.91 , whereas the correlation between the

418 Strength and Individuation Indices was 0.73 , a significant difference $(z=5.62, p=$

$4192.0 \times 10^{-8}$, using $z$-test with $\mathrm{N}=180$ (Fisher, 1921)). Given comparable reliabilities for all

420 measures, this difference unlikely results from measurement noise - rather it suggests

421 that our Strength and Individuation Indices measure two different aspects of the hand

422 function, whereas the clinical scales tend to capture a mixture of strength and control.

424 Recovery of strength and individuation occurred mainly in the first three months after

425 stroke.

426 We first examined the time courses of recovery for strength and individuation in

427 the paretic hand. If the two observed variables change in parallel, their recovery may or

428 may not be mediated by the same underlying process. A difference in the time courses,

429 however, would provide a strong hint of separate recovery processes for strength and

430 individuation. 
432 weeks after stroke (Fig. 2A-B). A model with a fixed effect of Week and a random effect

433 of Subject was built to evaluate this statistically. An effect of Week was tested with a

434 likelihood ratio test against the null model with the random effect only. Results indicate

435 that both the Strength and Individuation Indices significantly improved over time

436 (Strength: $\chi^{2}=47.65, p=5.10 \times 10^{-12}$; Individuation: $\chi^{2}=18.58, p=1.63 \times 10^{-5}$ ). Paired $t$ -

437 tests between adjacent time points showed significant improvement (after Bonferroni

438 correction) of the Strength Index up to week 12; whereas the Individuation Index only

439 showed a significant improvement between weeks 4-12 (see detailed statistics in Fig. 2A-

440 B). A similar recovery curve was found for the standard clinical measures of motor

441 function (detailed statistics in Fig. 3).

442 To directly compare the time courses of between the two indices at the early stage

443 of recovery, we $z$-normalized scores of the two variables and then investigated the change

444 in the scores for the time intervals W1-4 vs. W4-12 (Fig. 2C). This analysis suggests that

445 strength may recover mostly in the first four weeks, while individuation recovery may

446 occur equally in both time periods. Repeated-measures ANOVA over z-scores for

447 Strength and Individuation Indices during the two time intervals yielded a significant

448 interaction $(F(1,25)=6.82, p=0.015$, Fig. $2 C)$. Thus, despite overall similarity, there

449 was a significant difference in the time courses of recovery of strength and individuation,

450 with strength showing faster early recovery.

451 That most improvement in both strength and individuation occurred over the first

45212 weeks is also apparent in the correlations between adjacent testing time points for each

453 variable across individuals (Fig. 2D). The correlation between weeks 1 and 4 for the 
454 Individuation Index was significantly lower than it was for subsequent time points (W1-4

455 vs. W24-52: $z=-4.23, p=0.000023)$, and this difference for Strength Index was

456 marginally significant $(z=-1.83, p=0.067)$, using $z$-test with $\mathrm{N}=28$ and 33 (Fisher,

457 1921). Thus, the position of the patients on the mean recovery curve changed more

458 during the first 4 weeks than in the last 6 months. This correlation difference cannot be

459 attributed to measurement noise, as both measures had stable reliabilities at all time

460 points (dashed line). Instead, the lack of stability of these measures during early recovery

461 is indicative of meaningful biological change.

462

Insert Figure 2

466 showed mild impairment in the first month after stroke. A likelihood ratio test of the

467 mixed-effect model showed a significant effect of Week for Strength $\left(\chi^{2}=7.86, p=\right.$

$4680.0051)$, and a more subtle effect for Individuation $\left(\chi^{2}=4.12, p=0.042\right)$ (Fig. 2A-B).

469 This increase in performance is unlikely to be related to a general practice effect, because

470 the Strength Index in healthy controls decreased slightly over time $\left(\chi^{2}=4.54, p=0.033\right)$,

471 perhaps due to reduced effort, whereas the Individuation Index for healthy controls was

472 maintained at a similar level over the whole year $\left(\chi^{2}=0.33, p=0.56\right)$. 
477 three months after stroke, with stabilization of recovery around 3-6 months. The data also

478 suggest a slight difference in the time course, with strength recovering faster than

479 individuation in the first month.

481 Evidence for a time-invariant relationship between strength and control.

482 The time course analysis only provides weak evidence for partial independence of

483 the recovery processes for strength and individuation. Therefore we undertook a closer

484 examination of the relationship between the two variables at each testing time-point (Fig.

485 4A). Although patients tended to move from the lower left corner to the upper right

486 corner of this space over the time course of recovery, the overall shape of the strength-

487 individuation impairment relationship seemed to be remarkably preserved across weeks.

488 At lower strength levels, there was a clear correlation between strength and individuation;

489 whereas once above $\sim 60 \%$ of normal strength level, the two variables were unrelated,

490 producing a distinct curvilinear shape for the overall function (Fig. 4B).

491 To formally test the time invariance suggested by visual inspection, we first found

492 a function to describe the strength-individuation relationship. We used data from all time

493 points and evaluated the goodness of fit of a piecewise function with two linear segments

494 connected at an inflection point, using leave-one-out cross-validation (see Materials and

495 Methods). Cross-validation automatically penalizes models that are too complex. This

496 functional form gave us a good fit to the data (cross-validated $R^{2}=0.53$, Fig. 4B). We

497 also explored first- to fourth- order polynomial functions. All four models resulted in a

498 worse fit (cross-validated $\left.R^{2}<0.49\right)$ than the piece-wise linear function. 
We then tested for "time-invariance" of this strength-control relationship, that is,

500 whether the function shape changed across weeks. Again, using leave-one-out cross-

501 validation, the time-invariant model with fixed parameters across all weeks was

502 compared with a model that allowed the parameters to change for each week (time-

503 varying model). The cross-validated $R^{2}$ for the time-varying two-segment piecewise

504 linear function was 0.45 , a worse fit than the time-invariant model.

505 These results suggest that there is a time-invariant recovery relationship between

506 strength and individuation after stroke, which consists of two parts: up to a certain level

507 of strength $(60.7 \%$ of non-paretic hand), the Strength and Individuation Indices are

508 strongly correlated $\left(r=0.74, p=6.61 \times 10^{-18}\right)$; after strength exceeds this threshold, the

509 two variables are no longer correlated $(r=-0.17, p=0.11$; Fig 4B). This lack of

510 correlation cannot be attributed to a ceiling effect for the Individuation Index, because for

511 both patients and controls there was still a considerable variability, and the reliability of

512 Individuation Index was very high. This indicates that our measure has enough dynamic

513 range and sensitivity to detect inter-individual differences even in the healthy population.

518 time-invariant function relating strength and individuation. Differences in recovery arise

519 because patients vary substantially in the distance they move along this function: some

520 patients with initial severe impairment made a good recovery, moving past the inflection

521 point of $60.7 \%$ strength (exemplified by the yellow dot in Fig. 4A). Other severely 
522 impaired patients failed to reach the inflection point (red dot in Fig. 4A). Finally, some

523 mildly impaired patients started off beyond the inflection point and showed a good range

524 of individuation capacity.

A second process contributed additional recovery of finger individuation.

The fact that recovery of both strength and individuation could be captured by a

528 single time-invariant function that relates them is compatible with the hypothesis of a

529 single underlying process that drives recovery of both aspects of hand function. It is

530 possible, however, that an additional process injects further recovery, which determines a

531 patient's position relative to the mean recovery function in strength-individuation space.

532 If such a process exists, a given patient should occupy a consistent position above or

533 below the mean recovery function across time points.

534 To test this hypothesis we investigated the residuals of the Individuation Index for

535 each patient at each time point after subtracting out the mean two-segment piecewise-

536 linear recovery function. If the variability around this mean function were purely due to

537 noise, we should observe no consistent week-by-week correlation between residuals for

538 each patient. Alternatively, if the residuals were to be correlated across weeks, it would

539 indicate that some patients were consistently better at individuation than that predicted

540 from the function, and others were consistently worse, suggesting an additional factor

541 mediating individuation recovery (black arrows in Fig. 6).

542 Correlations of residuals from adjacent time points across patients were initially quite

543 low. However, from week 4 onwards, most patients' distances from the mean function

544 remained stable (Fig. 4C-D). This consistent structure in residuals provides evidence for 
545 an extra factor contributing to recovery of individuation. The consistent pattern of

546 residuals at later time points could not be attributed to pre-morbid inter-individual

547 differences, because both the Strength and Individuation Indices were normalized to the

548 non-paretic hand. The low week-by-week correlations between early time points argues

549 that the later correlations do not simply reflect sparing of a particular neural system after

550 the stroke. If this had been true, the correlation between the Individuation residuals

551 should have remained constant across all time points. Furthermore, the lower early

552 correlation cannot be attributed to measurement noise, as reliabilities for the early

553 measurement points were high (Fig. 4D). Rather, the initially low but then increasing

554 correlation indicates an additional recovery process operating above the lower bound of

555 the strength-individuation function (Fig. 6). This process is mostly active in the first three

556 months after stroke and determines how well individuation recovers above that expected

557 from the time-invariant recovery function.

559 Lesions involving motor cortex and the corticospinal tract correlated more with

560 individuation than strength.

561 To investigate the underlying neural substrates of recovery processes, we

562 correlated the location and size of the lesion with the Strength and Individuation Indices.

563 We were especially interested in the particular role of the corticospinal tract (CST).

564 While both corticospinal and corticoreticular projections originate in part from the

565 precentral gyrus and are intermingled to some degree, cortical projections to the reticular

566 formation have a more widespread bilateral origin from other pre-motor areas (Keizer

567 and Kuypers, 1989), whereas direct corticospinal projections to ventral horn neurons 
568 primarily arise from the anterior bank of the precentral gyrus/central sulcus, i.e. "new

569 M1" (Rathelot and Strick, 2009; Witham et al., 2016). We therefore predicted that extent

570 of the damage to the hand area of the primary motor cortex, and to the white matter ROI

571 that characterizes the most likely course of the CST (see Materials and Methods) would

572 correlate more with Individuation, and less with Strength. Furthermore, lesions in these

573 areas should correlate with individuation recovery over and above the level expected

574 from the mean recovery function.

575 As hypothesized, the extent of involvement by the lesion of the cortical hand area

576 correlated significantly with the Individuation Index at all time points. For the CST, all

577 correlations were significant after week 1 (Fig. 5B-D). While both lesion measures also

578 correlated with the Strength Index, these correlations were weaker (repeated-measures

579 ANOVA showed a significant main effect for behavioral measure $(F(1,3)=146, p=$

580 0.001). This difference was not due to measurement noise, as the Strength and

581 Individuation Indices had comparable reliabilities. Furthermore, percent lesion

582 involvement also significantly correlated with the Individuation Index, after accounting

583 for the average Strength-Individuation relationship $(p<0.05$ for correlations after week

58424 for cortical hand area, and after week 12 for CST). Indeed, at W52, the correlations

585 with the residuals were as high as with the Individuation Indices themselves $(r=0.61$ vs.

$586 r=0.57$ for the cortical hand area, $r=0.51$ vs. $r=0.54$ for the CST). Together these

587 results suggest that Individuation recovery is most heavily determined by the sparing in

588 the hand area of the primary motor cortex and of direct CST projections, while strength

589 recovery may also depend on other spared descending pathways. 


\section{Discussion}

595 In a large-scale longitudinal study, we tracked recovery of two independent

596 behavioral components of hand function: strength and finger control. Patients were tested

597 at five time points over a one-year period after stroke, using a novel paradigm that

598 separately measures maximum voluntary contraction force (a measure of strength) and

599 finger individuation ability (a measure of control), and crucially controls for any

600 obligatory dependency between these two measures. This approach allowed us to

601 determine how recovery of strength and control interrelate. Our main question was to ask

602 whether there is a causal relationship between strength and control at the level of

603 recovery mechanisms, after the two variables had been experimentally uncoupled. If they

604 are truly dissociable, then hypothetically patients could show perfect control of individual

605 fingers, even with significant weakness (except for complete hemiplegia, in which case

606 no individuation measure would be obtainable).

607 We showed that involuntary movements in passive fingers (enslaving) increased

608 with the level of force production of the active finger. This phenomenon is analogous to

609 what Dewald and colleagues (Sukal et al., 2007; Ellis et al., 2009) have described for the

610 paretic arm: a decrease in arm reaching workspace as the force requirement to resist

611 gravity increases. We showed that the ratio of enslaving and active force can account for

612 this dependency and thereby provides a sensitive measure of finger control independent

613 of the level of force deficit. 
We first examined the time courses of recovery for strength and individuation.

615 Consistent with what has been described with traditional clinical scales (Duncan et al.,

616 1992; Jørgensen et al., 1995; Krakauer et al., 2012), both measures showed most

617 recovery over the first three months after stroke. This similarity between the time courses

618 does not, however, necessarily imply that recovery of strength and individuation is

619 dependent on a single underlying neural substrate or mechanism. It remains possible that

620 recovery of these two components occurs in parallel because of commonalities in basic

621 tissue repair mechanisms post-ischemia but they are nevertheless independent modules.

622 Indeed, we found a small but robust difference in the time course of recovery of strength

623 compared to control: finger strength showed a faster rate of change compared to

624 individuation over the first month. This finding raises the interesting possibility that

625 different neurological substrates underlie recovery of strength and individuation.

626 Closer examination of the two variables revealed a time-invariant non-linear

627 relationship between strength and individuation in the paretic hand. This function has two

628 distinct parts: individuation and strength were highly correlated below a strength

629 threshold of $\sim 60 \%$ of the non-paretic side; beyond this point, they were uncorrelated. The

630 shape of this function remained the same across all time points. Recovery of hand

631 function could be characterized as movement along this invariant function: patients with

632 good recovery traveled further along the function, whereas patients with poor recovery

633 remained in the first segment. The strong correlation between strength and individuation

634 for severely impaired patients is consistent with a single system mediating recovery of

635 both. Indeed, in our cohort there was no patient with relatively good strength but severe

636 impairment of individuation, which also suggests that recovery of finger control 
637 correlates with recovery of strength in patients with severe hemiparesis. However, two

638 pieces of behavioral evidence suggest that strength and finger control might rely on

639 partially separate mechanisms of recovery. First, a correlation between strength and

640 individuation was absent for the subset of well-recovered patients - i.e. patients with a

641 Strength Index above $60 \%$. This breakdown in correlation cannot be attributed to a

642 ceiling effect for Individuation. Secondly, analysis of the residuals around the mean

643 recovery function revealed that patients differed consistently in the amount of their

644 individuation recovery relative to the level predicted by their strength recovery. Notably,

645 their positioning relative to the mean recovery curve seemed to be set early in the

646 recovery process and then remained relatively stable at later time points.

651 partially separate systems. One system primarily contributes strength, but also has some

652 limited control capacity. The isolated contribution of this system would determine the

653 lower bound of the data points in the strength-individuation plot (dashed line in Fig. 6):

654 when a patient regains some strength, he or she automatically regains a limited amount of

655 control with it. However, the amount of individuation is limited and does not increase

656 above a certain level. This would explain both the strong correlation between strength

657 and individuation for the severely impaired patients, and the fact that no patient occupied

658 the lower right corner of strength-individuation space, i.e. no patients had good strength

659 but minimal control. 
661 (vertical arrows in Fig. 6). Patients with a strong contribution from this second system

662 may gain full recovery of individuation; patients with no or only partial contribution from

663 the second system may recover completely in strength, but not in individuation.

664 Importantly the recovery of this second system also occurs early after stroke,

665 subsequently a patient's relative position above or below the mean recovery function

666 remains relatively fixed (Fig. 4D).

667 The lesion analysis adds support to the two-systems model for recovery suggested

668 by the behavioral data. A wealth of evidence in humans and non-human primates

669 implicates the role of CST in finger control, especially the monosynaptic cortico-

670 motoneuronal connections originating from "new” M1 (Lawrence and Kuypers, 1968;

671 Porter and Lemon, 1993; Rathelot and Strick, 2009). Notably, these connections do not

672 generate high levels of force but rather finely graded forces riding on top of larger forces

673 (Maier et al., 1993). Consistent with this idea, lesions in the gray matter of the hand areas

674 in M1- the main origin of corticospinal projections- as well as the CST, correlated more

675 with impaired individuation than with strength.

676 In contrast, finger strength may rely on other neural pathways, including the

677 reticulospinal tract (RST), which can support strength and gross movements (Buford and

678 Davidson, 2004; Davidson and Buford, 2004). Although the RST has been found to

679 participate in some degree of finger control, its functional range is limited and biased

680 towards flexor muscles (Riddle et al., 2009; Baker, 2011).

681 Recovery after stroke is likely to result from the dynamic interplay between the

682 CST and other descending pathways, particularly the RST. In this scenario, the 
683 correlation between strength and control at low levels of strength may represent the state

684 of both the residual CST and of cortical projections to reticular nuclei in the brainstem. In

685 this framework, recovery along the lower bound of the invariant function would represent

686 the contribution of the RST and other non-CST descending pathways. Those patients

687 with less damage to the CST would consistently ride above this function.

688 The dichotomy proposed here may be too simplistic. While the origin of the

689 corticoreticular inputs is more diffuse (Keizer and Kuypers, 1989) and bi-laterally

690 organized (Buford and Davidson, 2004; Sakai et al., 2009; Soteropoulos et al., 2012),

691 many of the projections to the reticular formation arise from the primary motor cortex

692 (Catsman-Berrevoets and Kuypers, 1976; Jones and Wise, 1977). Thus, our lesion ROIs

693 will have included the corticoreticular tract to some degree, possibly explaining the

694 lower, but nevertheless significant correlation with strength. Furthermore, it is very likely

695 that direct corticospinal projections contribute to hand strength to some degree.

696 Interestingly, there was a small degree of impairment, especially in strength, in

697 the hand ipsilesional to the stroke. This finding confirms previous reports of deficits in

698 the non-paretic hand using clinical scales, e.g. muscle weakness measured by

699 dynamometry (Colebatch and Gandevia, 1989), and dexterity measured with the Nine

700 Hole Peg Test (9HPT) in (Noskin et al., 2008). This ipsilesional impairment is consistent

701 with positing a strength role for the RST because it projects bilaterally.

702 A limitation of the current study is that the paradigm is designed to assess

703 weakness and enslaving in finger flexors, but not extensors. Because finger extensors

704 play an important role in finger individuation, and have been particularly associated with

705 the CST, it is possible that individuation in the extensors would also be more CST- 
706 dependent and the dual systems we are implying for the flexor might not apply to the

707 same degree.

708

709

\section{Conclusions}

710 Here we found that hand function after stroke can be partitioned into strength and

711 strength-independent control. Most recovery of both these components occurred in the

712 first three months after stroke, although strength continued to improve for up to six

713 months. At any time point after stroke, strength and strength-independent control were

714 related by an invariant curvilinear function: strength and some degree of control are

715 correlated up to a certain strength level and then control saturates; some subjects showed

716 additional improvement in individuation riding on top of the main recovery function. The

717 results suggest that hand recovery is supported by two separable systems: one that mainly

718 contributes to the generation of large forces, as in the power grip, and another that is

719 responsible for more precise control of the digits at all levels of force. This behavioral

720 and imaging evidence for two systems contributing to recovered hand function after

721 stroke is consistent with the known characteristics of the CST and RST. 


\section{References}

725 Baker SN. The primate reticulospinal tract, hand function and functional recovery. J.

$726 \quad$ Physiol. 2011; 589: 5603-5612.

727 Bates D, Mächler M, Bolker B, Walker S. Fitting Linear Mixed-Effects Models using

$728 \quad$ lme4.

729 Brainard DH. The Psychophysics Toolbox. Spat. Vis. 1997; 10: 433-436.

730 Buford JA, Davidson AG. Movement-related and preparatory activity in the

731 reticulospinal system of the monkey. Exp. Brain Res. 2004; 159: 284-300.

732 Catsman-Berrevoets CE, Kuypers HG. Cells of origin of cortical projections to dorsal

733 column nuclei, spinal cord and bulbar medial reticular formation in the rhesus

734 monkey. Neurosci. Lett. 1976; 3: 245-252.

735 Ceritoglu C, Oishi K, Li X, Chou M-C, Younes L, Albert M, et al. Multi-contrast large

736 deformation diffeomorphic metric mapping for diffusion tensor imaging.

$737 \quad$ NeuroImage 2009; 47: 618-627.

738 Colebatch JG, Gandevia SC. The Distribution of Muscular Weakness in Upper Motor

$739 \quad$ Neuron Lesions Affecting the Arm. Brain 1989; 112: 749-763.

740 Dale AM, Fischl B, Sereno MI. Cortical surface-based analysis. I. Segmentation and

$741 \quad$ surface reconstruction. NeuroImage 1999; 9: 179-194.

742 Davidson AG, Buford JA. Motor outputs from the primate reticular formation to shoulder

743 muscles as revealed by stimulus-triggered averaging. J. Neurophysiol. 2004; 92:

$744 \quad 83-95$. 
745 Duncan PW, Goldstein LB, Matchar D, Divine GW, Feussner J. Measurement of motor

746 recovery after stroke. Outcome assessment and sample size requirements. Stroke

$747 \quad$ J. Cereb. Circ. 1992; 23: 1084-1089.

748 Ellis MD, Sukal-Moulton T, Dewald JPA. Progressive shoulder abduction loading is a

749 crucial element of arm rehabilitation in chronic stroke. Neurorehabil. Neural

$750 \quad$ Repair 2009; 23: 862-869.

751 Fischl B, Rajendran N, Busa E, Augustinack J, Hinds O, Yeo BTT, et al. Cortical folding

752 patterns and predicting cytoarchitecture. Cereb. Cortex N. Y. N 1991 2008; 18:

$753 \quad 1973-1980$.

754 Fisher RA. On the 'Probable Error' of a coefficient of correlation deduced from a small

755 sample. Metron 1921: 1-32.

756 Fugl-Meyer AR, Jääskö L, Leyman I, Steglind S. The post-stroke hemiplegic patient. 1. a

757 method for evaluation of physical performance. Scand. J. Rehabil. Med. 1975; 7:

$758 \quad 13-31$.

759 Guttman L. A basis for analyzing test-retest reliability. Psychometrika 1945; 10: 255-

$760 \quad 282$.

761 Heller A, Wade DT, Wood VA, Sunderland A, Hewer RL, Ward E. Arm function after

762 stroke: measurement and recovery over the first three months. J. Neurol.

$763 \quad$ Neurosurg. Psychiatry 1987; 50: 714-719.

764 Holland PW, Welsch RE. Robust regression using iteratively reweighted least-squares.

765 Commun. Stat. - Theory Methods 1977; 6: 813-827.

766 Jones EG, Wise SP. Size, laminar and columnar distribution of efferent cells in the

767 sensory-motor cortex of monkeys. J. Comp. Neurol. 1977; 175: 391-438. 

and time course of recovery in stroke. Part II: Time course of recovery. The copenhagen stroke study. Arch. Phys. Med. Rehabil. 1995; 76: 406-412.

771 Kamper DG, Harvey RL, Suresh S, Rymer WZ. Relative contributions of neural mechanisms versus muscle mechanics in promoting finger extension deficits following stroke. Muscle Nerve 2003; 28: 309-318.

774 Kamper DG, Rymer WZ. Impairment of voluntary control of finger motion following stroke: role of inappropriate muscle coactivation. Muscle Nerve 2001; 24: 673681.

783 Laird NM, Ware JH. Random-effects models for longitudinal data. Biometrics 1982; 38: 963-974.

785 Lang CE, Schieber MH. Differential impairment of individuated finger movements in 786 humans after damage to the motor cortex or the corticospinal tract. J. Neurophysiol. 2003; 90: 1160-1170.

788 Lang CE, Schieber MH. Reduced muscle selectivity during individuated finger

789 movements in humans after damage to the motor cortex or corticospinal tract. J.

$790 \quad$ Neurophysiol. 2004; 91: 1722-1733. 
791 Li S, Latash ML, Yue GH, Siemionow V, Sahgal V. The effects of stroke and age on

792 finger interaction in multi-finger force production tasks. Clin. Neurophysiol. Off.

793 J. Int. Fed. Clin. Neurophysiol. 2003; 114: 1646-1655.

794 Li ZM, Latash ML, Zatsiorsky VM. Force sharing among fingers as a model of the

795 redundancy problem. Exp. Brain Res. 1998; 119: 276-286.

796 Lyden PD, Lau GT. A critical appraisal of stroke evaluation and rating scales. Stroke J.

$797 \quad$ Cereb. Circ. 1991; 22: 1345-1352.

798 Maier MA, Bennett KM, Hepp-Reymond MC, Lemon RN. Contribution of the monkey

799 corticomotoneuronal system to the control of force in precision grip. J.

$800 \quad$ Neurophysiol. 1993; 69: 772-785.

801 Mori S, Oishi K, Jiang H, Jiang L, Li X, Akhter K, et al. Stereotaxic white matter atlas

802 based on diffusion tensor imaging in an ICBM template. NeuroImage 2008; 40:

$803 \quad 570-582$.

804 Noskin O, Krakauer JW, Lazar RM, Festa JR, Handy C, O’Brien KA, et al. Ipsilateral

805 motor dysfunction from unilateral stroke: implications for the functional

806 neuroanatomy of hemiparesis. J. Neurol. Neurosurg. Psychiatry 2008; 79: 401-

$807 \quad 406$.

808 Oishi K, Faria A, Jiang H, Li X, Akhter K, Zhang J, et al. Atlas-based whole brain white

809 matter analysis using large deformation diffeomorphic metric mapping:

810 application to normal elderly and Alzheimer's disease participants. NeuroImage

$811 \quad 2009 ; 46: 486-499$.

812 Oishi K, Faria AV, van Zijl PC, Mori S. MRI atlas of human white matter. Academic

$813 \quad$ Press; 2010. 
814 Oishi K, Zilles K, Amunts K, Faria A, Jiang H, Li X, et al. Human brain white matter

815 atlas: identification and assignment of common anatomical structures in

$816 \quad$ superficial white matter. NeuroImage 2008; 43: 447-457.

817 Oldfield RC. The assessment and analysis of handedness: the Edinburgh inventory.

$818 \quad$ Neuropsychologia 1971; 9: 97-113.

819 Picard RR, Cook RD. Cross-Validation of Regression Models. J. Am. Stat. Assoc. 1984;

$820 \quad 79: 575-583$.

821 Raghavan P, Krakauer JW, Gordon AM. Impaired anticipatory control of fingertip forces

822 in patients with a pure motor or sensorimotor lacunar syndrome. Brain 2006; 129:

$823 \quad 1415-1425$.

824 Rathelot J-A, Strick PL. Muscle representation in the macaque motor cortex: an

825 anatomical perspective. Proc. Natl. Acad. Sci. U. S. A. 2006; 103: 8257-8262.

826 Rathelot J-A, Strick PL. Subdivisions of primary motor cortex based on cortico-

827 motoneuronal cells. Proc. Natl. Acad. Sci. 2009; 106: 918-923.

828 Reinkensmeyer DJ, Lum PS, Lehman SL. Human control of a simple two-hand grasp.

829 Biol. Cybern. 1992; 67: 553-564.

830 Riddle CN, Edgley SA, Baker SN. Direct and indirect connections with upper limb

831 motoneurons from the primate reticulospinal tract. J. Neurosci. Off. J. Soc.

$832 \quad$ Neurosci. 2009; 29: 4993-4999.

833 Sakai ST, Davidson AG, Buford JA. Reticulospinal neurons in the pontomedullary

834 reticular formation of the monkey (Macaca fascicularis). Neuroscience 2009; 163:

$835 \quad 1158-1170$. 
836 Schieber MH. Individuated finger movements of rhesus monkeys: a means of quantifying

837 the independence of the digits. J. Neurophysiol. 1991; 65: 1381-1391.

838 Sharpless JW. The nine hole peg test of finger hand coordination for the hemiplegic

839 patient. Mossmans Probl. Orientated Approach Stroke Rehabil. 1982

840 Soteropoulos DS, Williams ER, Baker SN. Cells in the monkey ponto-medullary reticular

841 formation modulate their activity with slow finger movements. J. Physiol. 2012;

$842 \quad$ 590: 4011-4027.

843 Sukal TM, Ellis MD, Dewald JPA. Shoulder abduction-induced reductions in reaching

844 work area following hemiparetic stroke: neuroscientific implications. Exp. Brain

$845 \quad$ Res. 2007; 183: 215-223.

846 Sunderland A, Tinson D, Bradley L, Hewer RL. Arm function after stroke. An evaluation

847 of grip strength as a measure of recovery and a prognostic indicator. J. Neurol.

$848 \quad$ Neurosurg. Psychiatry 1989; 52: 1267-1272.

849 Witham CL, Fisher KM, Edgley SA, Baker SN. Corticospinal Inputs to Primate

850 Motoneurons Innervating the Forelimb from Two Divisions of Primary Motor

851 Cortex and Area 3a. J. Neurosci. Off. J. Soc. Neurosci. 2016; 36: 2605-2616.

852 Yousry TA, Schmid UD, Alkadhi H, Schmidt D, Peraud A, Buettner A, et al.

853 Localization of the motor hand area to a knob on the precentral gyrus. A new

854 landmark. Brain J. Neurol. 1997; 120 ( Pt 1): 141-157.

855 Zatsiorsky VM, Li ZM, Latash ML. Enslaving effects in multi-finger force production.

$856 \quad$ Exp. Brain Res. 2000; 131: 187-195. 
bioRxiv preprint doi: https://doi org/10 1101/079269; this version posted October 7, 2016. The copyright holder for this preprint (which was not certified by peer review) is the author/funder, who has granted bioRxiv a license to display the preprint in perpetuity. It is made available under aCC-BY-NC-ND 4.0 International license.

857 Zhang Y, Zhang J, Oishi K, Faria AV, Jiang H, Li X, et al. Atlas-guided tract

858 reconstruction for automated and comprehensive examination of the white matter

859 anatomy. NeuroImage 2010; 52: 1289-1301.

860

861 
bioRxiv preprint doi: https://doi.org/10.1101/079269; this version posted October 7, 2016. The copyright holder for this preprint (which was not

certified by peer review) is the author/funder, who has granted bioRxiv a license to display the preprint in perpetuity. It is made available under aCC-BY-NC-ND 4.0 International license.

862 Table 1. Patient characteristics: age (years), sex, paretic side, initial FMA (Fugl-Meyer

863 arm score, maximum 66), initial MoCA (Montreal Cognitive Assessment, maximum 30).

864

865 Table 2. Correlation between Strength Index, Individuation Index, FMA (Fugl-Meyer

866 arm score, maximum 66), and ARAT (Action Reach Arm Test, maximum 57). All four

867 measures are highly correlated; however Strength and Individuation Indices show the

868 weaker correlation compared to that between FMA and ARAT.

869 


\begin{tabular}{|c|c|c|c|c|c|}
\hline Patient & $\begin{array}{l}\text { Age at } \\
\text { stroke }\end{array}$ & Gender & $\begin{array}{c}\text { Paretic } \\
\text { Side }\end{array}$ & $\begin{array}{c}\text { Initial } \\
\text { impairment } \\
\text { (FMA) }\end{array}$ & $\begin{array}{r}\text { Initial } \\
\text { MoCA }\end{array}$ \\
\hline 1 & 57 & $\mathrm{M}$ & $\mathrm{R}$ & 48 & 27 \\
\hline 2 & 24 & M & $\mathrm{L}$ & 35 & 23 \\
\hline 3 & 67 & $\mathrm{~F}$ & $\mathrm{R}$ & 16 & 23 \\
\hline 4 & 74 & $\mathrm{~F}$ & $\mathrm{R}$ & 39 & 17 \\
\hline 5 & 61 & $\mathrm{~F}$ & $\mathrm{~L}$ & 48 & 26 \\
\hline 6 & 59 & $\mathrm{~F}$ & $\mathrm{R}$ & 60 & 28 \\
\hline 7 & 57 & M & $\mathrm{R}$ & 54 & 27 \\
\hline 8 & 66 & M & $\mathrm{L}$ & 65 & 25 \\
\hline 9 & 42 & $\mathrm{~F}$ & $\mathrm{R}$ & 5 & 18 \\
\hline 10 & 65 & M & $\mathrm{L}$ & 30 & 25 \\
\hline 11 & 66 & $\mathrm{~F}$ & $\mathrm{~L}$ & 60 & 19 \\
\hline 12 & 51 & M & $\mathrm{L}$ & 34 & 25 \\
\hline 13 & 63 & $\mathrm{~F}$ & $\mathrm{~L}$ & 57 & 26 \\
\hline 14 & 55 & M & $\mathrm{L}$ & 0 & 26 \\
\hline 15 & 56 & M & $\mathrm{L}$ & 38 & 25 \\
\hline 16 & 56 & M & $\mathrm{L}$ & 64 & 24 \\
\hline 17 & 64 & $\mathrm{~F}$ & $\mathrm{R}$ & 20 & 16 \\
\hline 18 & 60 & $\mathrm{~F}$ & $\mathrm{R}$ & 55 & 21 \\
\hline 19 & 64 & M & $\mathrm{L}$ & 63 & 25 \\
\hline 20 & 25 & $\mathrm{~F}$ & $\mathrm{~L}$ & 42 & 29 \\
\hline 21 & 39 & $\mathrm{~F}$ & $\mathrm{~L}$ & 47 & 20 \\
\hline 22 & 46 & M & $\mathrm{L}$ & 9 & 27 \\
\hline 23 & 53 & $\mathrm{~F}$ & $\mathrm{~L}$ & 4 & 29 \\
\hline 24 & 66 & M & $\mathrm{L}$ & 59 & 24 \\
\hline 25 & 71 & M & $\mathrm{L}$ & 4 & 26 \\
\hline 26 & 52 & M & $\mathrm{L}$ & 53 & 24 \\
\hline 27 & 46 & M & $\mathrm{R}$ & 4 & 21 \\
\hline 28 & 46 & M & $\mathrm{L}$ & 49 & 30 \\
\hline 29 & 71 & M & $\mathrm{L}$ & 6 & 24 \\
\hline 30 & 47 & M & $\mathrm{R}$ & 57 & 10 \\
\hline 31 & 45 & M & $\mathrm{L}$ & 8 & 27 \\
\hline 32 & 55 & $\mathrm{~F}$ & $\mathrm{~L}$ & 19 & 25 \\
\hline 33 & 68 & $\mathrm{~F}$ & $\mathrm{~L}$ & 61 & $\mathrm{NaN}$ \\
\hline 34 & 65 & M & $\mathrm{L}$ & 32 & 28 \\
\hline 35 & 51 & $\mathrm{~F}$ & $\mathrm{~L}$ & 63 & 26 \\
\hline 36 & 42 & M & $\mathrm{R}$ & 54 & 25 \\
\hline 37 & 58 & M & $\mathrm{L}$ & 4 & 24 \\
\hline 38 & 41 & $\mathrm{~F}$ & $\mathrm{~L}$ & 4 & 23 \\
\hline 39 & 35 & M & $\mathrm{L}$ & 4 & 29 \\
\hline 40 & 68 & M & $\mathrm{L}$ & 52 & 27 \\
\hline 41 & 76 & M & $\mathrm{L}$ & 53 & 18 \\
\hline
\end{tabular}


bioRxiv preprint doi: https://doi.org/10.1101/079269; this version posted October 7, 2016. The copyright holder for this preprint (which was not certified by peer review) is the author/funder, who has granted bioRxiv a license to display the preprint in perpetuity. It is made available under aCC-BY-NC-ND 4.0 International license.

\begin{tabular}{cccccc}
42 & 86 & $\mathrm{M}$ & $\mathrm{L}$ & 54 & 20 \\
43 & 48 & $\mathrm{M}$ & $\mathrm{L}$ & 16 & 25 \\
44 & 74 & $\mathrm{M}$ & $\mathrm{R}$ & 5 & 25 \\
45 & 80 & $\mathrm{~F}$ & $\mathrm{R}$ & 9 & 24 \\
46 & 64 & $\mathrm{~F}$ & $\mathrm{~L}$ & 58 & 19 \\
47 & 22 & $\mathrm{M}$ & $\mathrm{R}$ & 63 & 27 \\
48 & 88 & $\mathrm{~F}$ & $\mathrm{R}$ & 55 & 28 \\
49 & 22 & $\mathrm{M}$ & $\mathrm{R}$ & 63 & 27 \\
50 & 87 & $\mathrm{~F}$ & $\mathrm{R}$ & 50 & 28 \\
51 & 84 & $\mathrm{M}$ & $\mathrm{R}$ & 30 & 26 \\
52 & 53 & $\mathrm{M}$ & $\mathrm{R}$ & 30 & 29 \\
53 & 54 & $\mathrm{M}$ & $\mathrm{L}$ & 59 & 21 \\
54 & 58 & $\mathrm{M}$ & $\mathrm{R}$ & 61 & 23 \\
\hline
\end{tabular}

871 
bioRxiv preprint doi: https://doi.org/10.1101/079269; this version posted October 7, 2016. The copyright holder for this preprint (which was not certified by peer review) is the author/funder, who has granted bioRxiv a license to display the preprint in perpetuity. It is made available under aCC-BY-NC-ND 4.0 International license.

872

873

\begin{tabular}{c|cccc}
\hline & $\begin{array}{c}\text { Strength } \\
\text { Index }\end{array}$ & $\begin{array}{c}\text { Individuation } \\
\text { Index }\end{array}$ & FMA & ARAT \\
\hline $\begin{array}{c}\text { Strength } \\
\text { Index }\end{array}$ & & 0.73 & 0.76 & 0.74 \\
\hline $\begin{array}{c}\text { Individuation } \\
\text { Index }\end{array}$ & & & 0.68 & 0.72 \\
\hline FMA & & & & 0.91 \\
\hline
\end{tabular}


874 Figure 1. Strength and Individuation task. (A) Ergonomic hand device. The participant's

875 fingers are securely placed on the keys using Velcro straps. (B) Computer screen

876 showing the instructional stimulus, which indicates both which finger to press and how

877 much force to produce (height of the green bar). In the MVF task, maximal force was

878 required; in the Individuation task a specific force level had to be reached. (C, D)

879 Example trials from two healthy control participants during the Individuation task. Four

880 trials are shown, one at $20 \%$ and one at $80 \%$ of MVF for the two participants. In this

881 case the fourth finger (red) was the active finger. Note the higher level of enslaving of the

882 passive fingers for higher active force level. (E) Mean deviation from baseline in the

883 passive fingers plotted against the force generated by the active finger for $(C)$ and $(D)$.

884 Increased enslaving with higher active force levels is clearly visible. The Individuation

885 Index is the -log(slope) of the regression line between active force and passive mean

886 deviation, measured as root mean square (RMS) force from baseline force produced by

887 passive fingers.

889 Figure 2. Temporal profiles of recovery for strength and individuation. $(\boldsymbol{A}-\boldsymbol{B})$ Group

890 recovery curves for the Strength and Individuation Indices for patients and controls.

891 Asterisks indicate significant week-to-week change for the paretic hand (Bonferroni

892 corrected p-values for each segments of Strength Index: $p(W 1-4)=0.0045, p(W 4-12)=$

$8930.0082, p(W 12-24)=0.068, p(W 24-52)=0.87 ;$ Individuation Index: $: p(W 1-4)=0.81$,

$894 p(W 4-12)=0.0024, p(W 12-24)=1.92, p(W 24-52)=2.91)$. (C) Rate of change (i.e.,

895 change per week) in Z-normalized Strength and Individuation Indices during the first two

896 intervals (Week 1 to 4 and Week 4 to 12). The two intervals show a significant interaction 
897 between strength and individuation, indicating faster initial improvement of strength; (D)

898 Week-to-week correlations between adjacent time points for the Strength and

899 Individuation Indices. Dashed lines are the noise ceilings based on the within-session

900 split-half reliabilities.

901

902 Figure 3. Temporal recovery profiles measures with clinical assessments. (A) Fugl-

903 Meyer for the arm (FMA) and (B) hand (FMH); (C) ARAT; (D-F) strength for hand grip,

904 FDI, and FCR muscles, as measured by Dynamometry. All measures showed significant

905 change over time for the paretic hand. FMA: $\chi^{2}=37.73, p=8.13 \times 10^{-10} ; F M H: \chi^{2}=$

$90629.03, p=7.14 \times 10^{-8} ;$ ARAT: $\chi^{2}=36.33, p=1.67 \times 10^{-9} ;$ grip $: \chi^{2}=33.02, p=9.21 \times 10^{-9}$;

$907 \quad$ FDI: $\chi^{2}=19.21, p=1.67 \times 10^{-5} ; F C R: \chi^{2}=28.47, p=9.50 \times 10^{-8}$.

908

909 Figure 4. Time-invariant impairment function relating strength and control. (A) Scatter

910 plots for Individuation against Strength Indices at each time point. Each black dot is one

911 patient's data; blue dots and ellipse indicates the mean and standard error for controls at

912 the time point. Two patients' data are highlighted: one with good recovery (yellow dot)

913 and one with poor recovery (red dot). (B) Scatter plot with data from all time points

914 superimposed with the best fitting two-segment piecewise-linear function with one

915 inflection point at Strength Index $=0.607$. (C) Residuals from each week subtracting out

916 the mean impairment function ( $B$, red line). The tendency of the residuals to stay above

917 or below the typical Strength-Individuation relationship indicates that there are stable

918 factors that determine Individuation recovery over and above strength recovery. (D)

919 Correlations of residuals from (C) across adjacent time points increased over time 
920 (Bonferroni corrected $p(W 1-4)=2.12, p(W 4-12)=0.00064, p(W 12-24)=0.0024$,

$\left.921 p(W 24-52)=p=3.39 \times 10^{-6}\right)$. Dashed line is the noise ceilings based on the within-

922 session split-half reliabilities.

923

924 Figure 5. Lesion distribution and correlation with behavior. (A) Averaged lesion

925 distribution mapped to JHU-MNI space (see Materials and Methods), with lesion flipped

926 to one hemisphere. Color bar indicates patient count. (B) Correlation of behavior

927 measures (Strength and Individuation Indices) at each time point with the percentage of

928 damaged cortical gray matter within the M1 hand area ROI, corticospinal tract (CST).

929 (D) Mean of week-by-week correlations between the two behavior measures and percent

930 lesion volume measures for the cortical gray matter hand area and CST ROI. Black

931 asterisks indicate significant correlations (tested against zero), and red asterisks indicate

932 a significant difference between the correlation for Strength and Individuation for each

933 week $(p<0.005)$.

934

935 Figure 6. A schematic diagram of the hypothesis of two recovery systems. The first

936 system (basic strength recovery) underlies strength recovery and a restricted amount of

937 individuation recovery. This system therefore defines the lower bound (dashed line) of the

938 space occupied by recovering patients (gray clound). A second system (additional

939 inidividuation recovery) adds further individuation abilities on top of the basic strength

940 recovery.

941

942 
bioRxiv preprint doi: https://doi.org/10.1101/079269; this version posted October 7, 2016. The copyright holder for this preprint (which was not certified by peer review) is the author/funder, who has granted bioRxiv a license to display the preprint in perpetuity. It is made available under aCC-BY-NC-ND 4.0 International license.

A

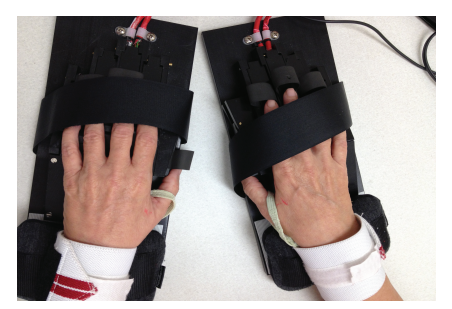

B

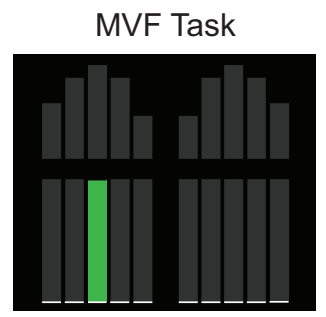

Individuation Task

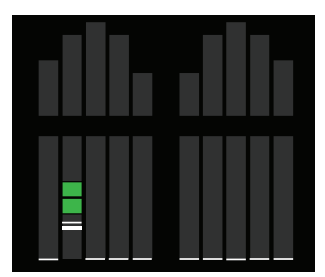

C

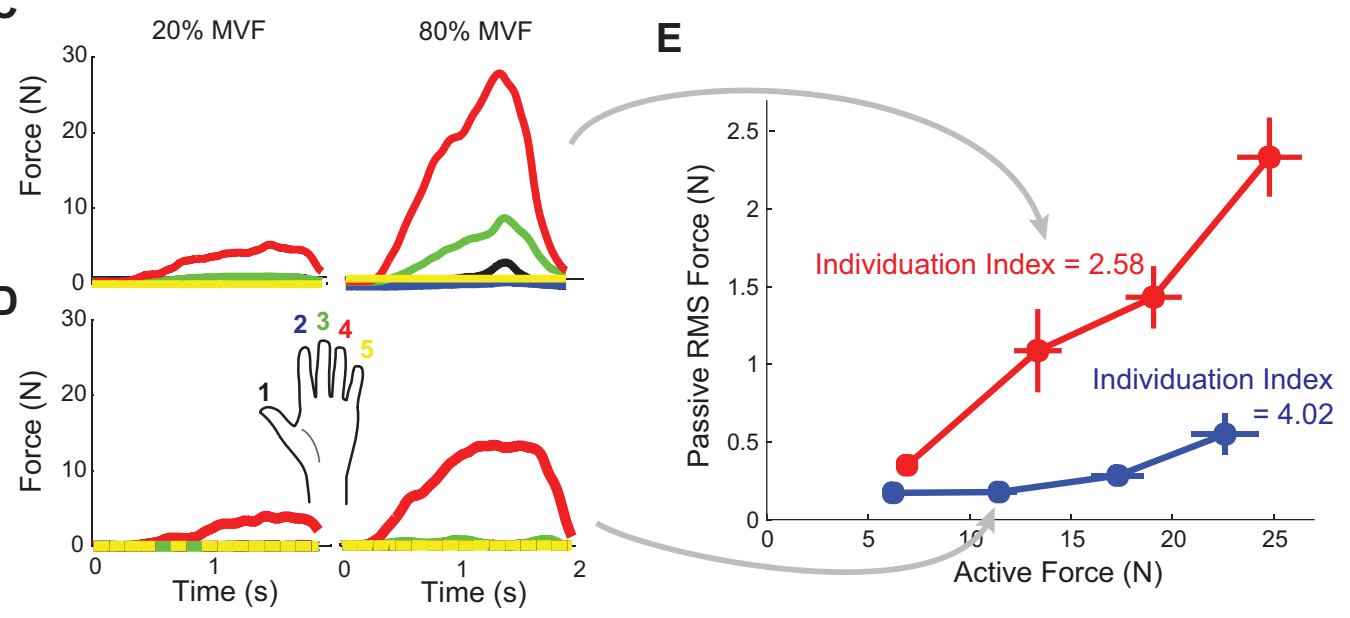


bioRxiv preprint doi: https://doi.org/10.1101/079269; this version posted October 7, 2016. The copyright holder for this preprint (which was not certified by peer review) is the author/funder, who has granted bioRxiv a license to display the preprint in perpetuity. It is made available under aCC-BY-NC-ND 4.0 International license.
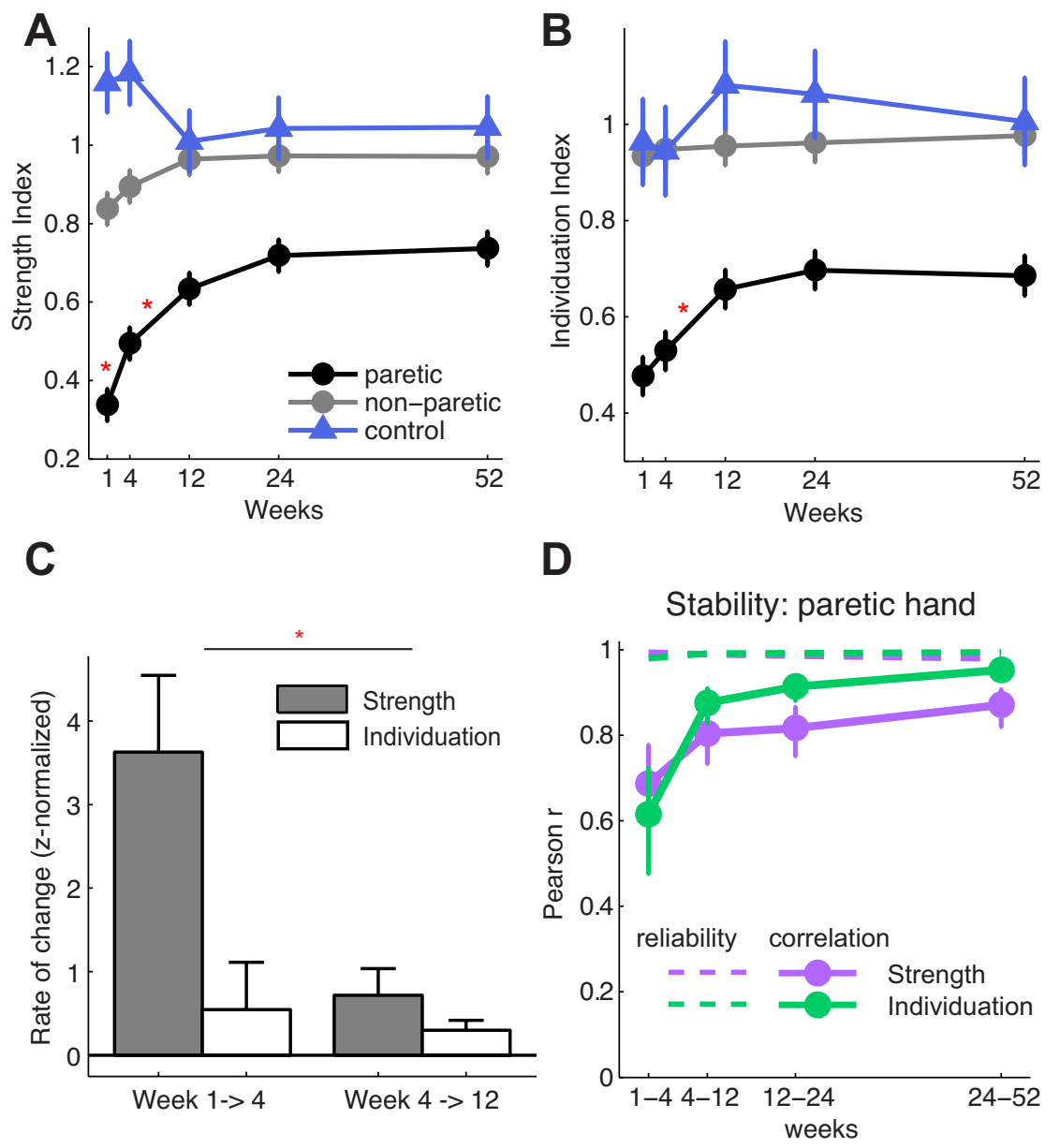

944 
bioRxiv preprint doi: https://doi.org/10.1101/079269; this version posted October 7, 2016. The copyright holder for this preprint (which was not certified by peer review) is the author/funder, who has granted bioRxiv a license to display the preprint in perpetuity. It is made available under aCC-BY-NC-ND 4.0 International license.

A

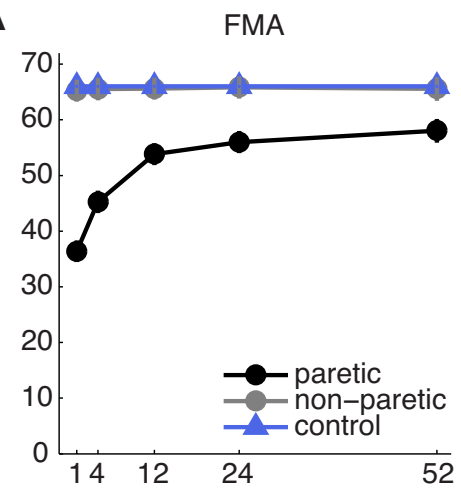

D

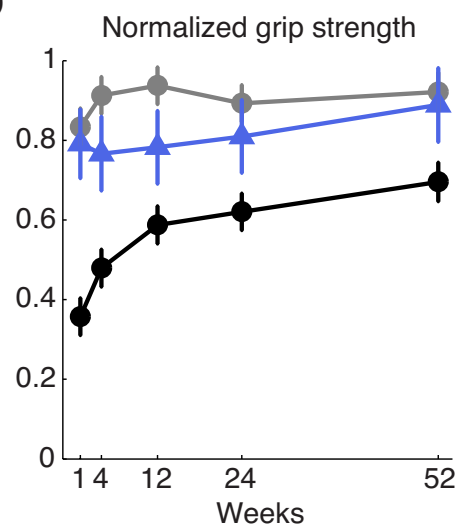

B

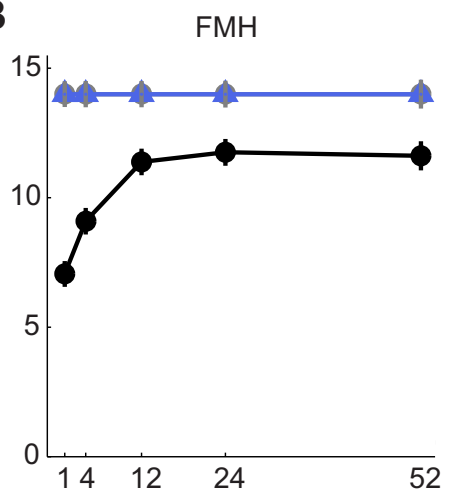

E

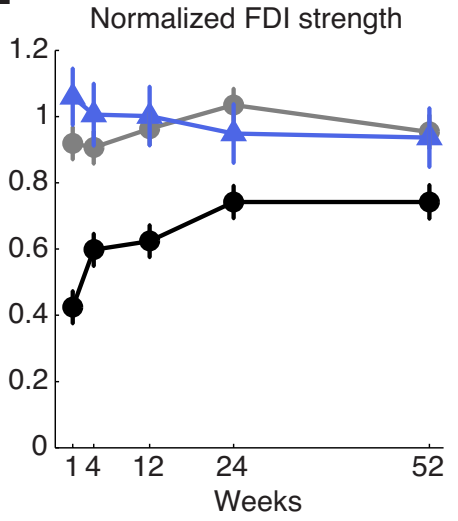

C

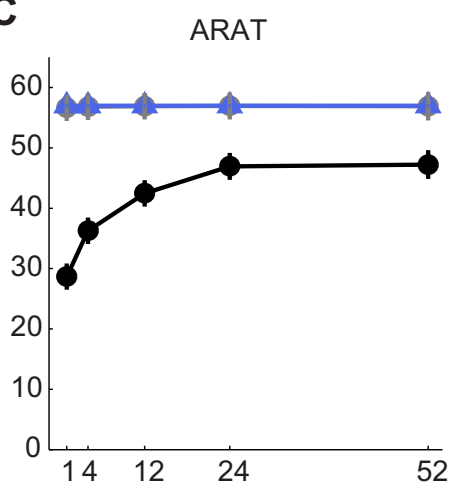

F

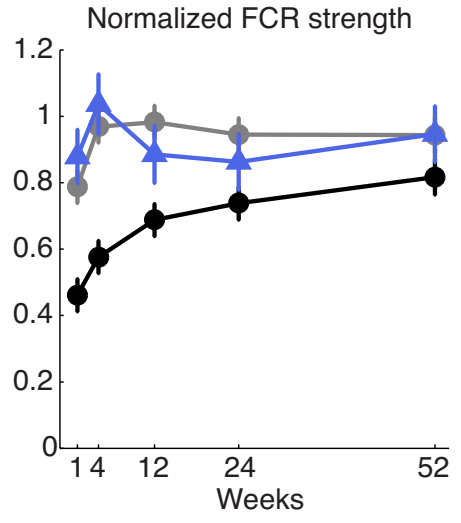

946 
bioRxiv preprint doi: https://doi.org/10.1101/079269; this version posted October 7, 2016. The copyright holder for this preprint (which was not certified by peer review) is the author/funder, who has granted bioRxiv a license to display the preprint in perpetuity. It is made available under aCC-BY-NC-ND 4.0 International license.

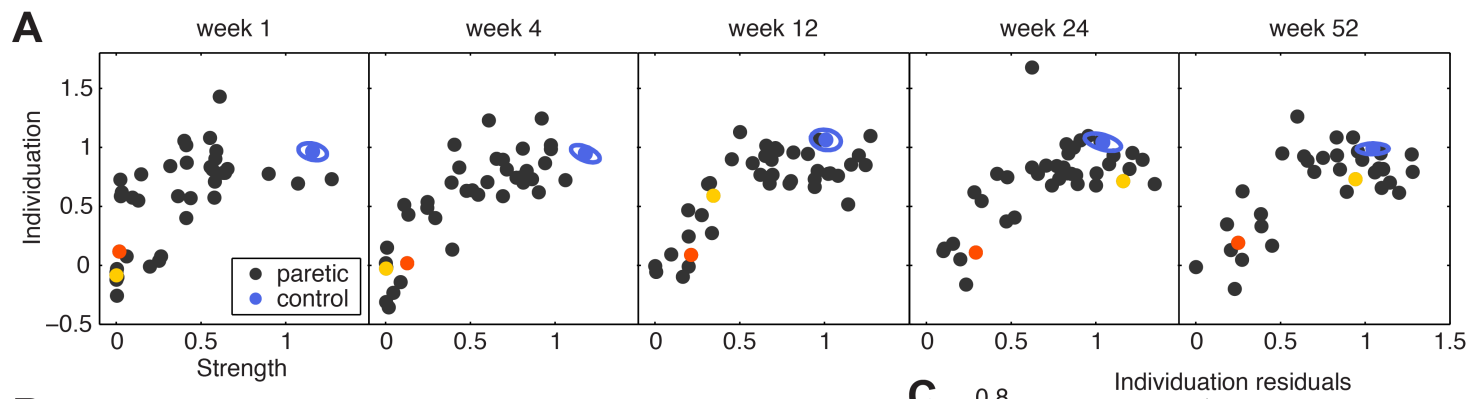

B

947

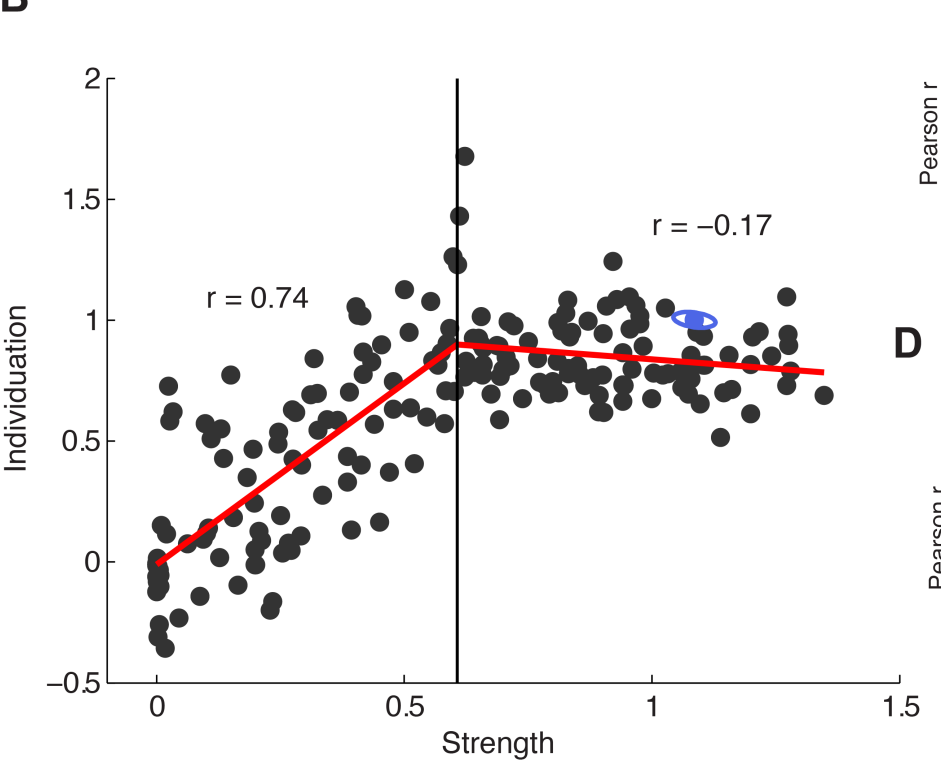

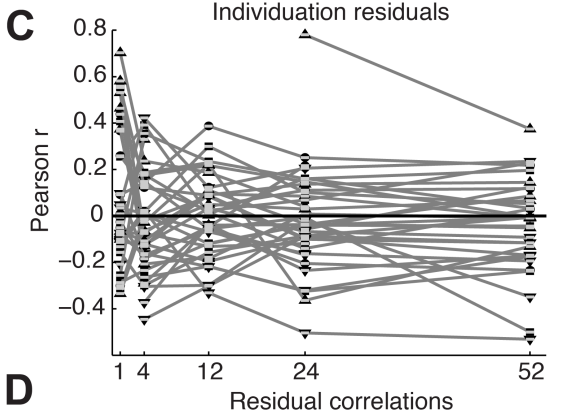

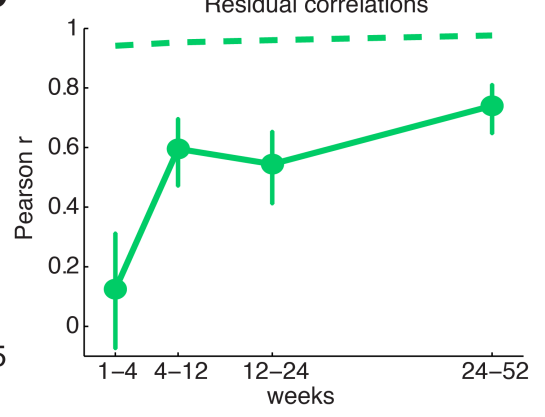


bioRxiv preprint doi: https://doi.org/10.1101/079269; this version posted October 7, 2016. The copyright holder for this preprint (which was not certified by peer review) is the author/funder, who has granted bioRxiv a license to display the preprint in perpetuity. It is made available under aCC-BY-NC-ND 4.0 International license.

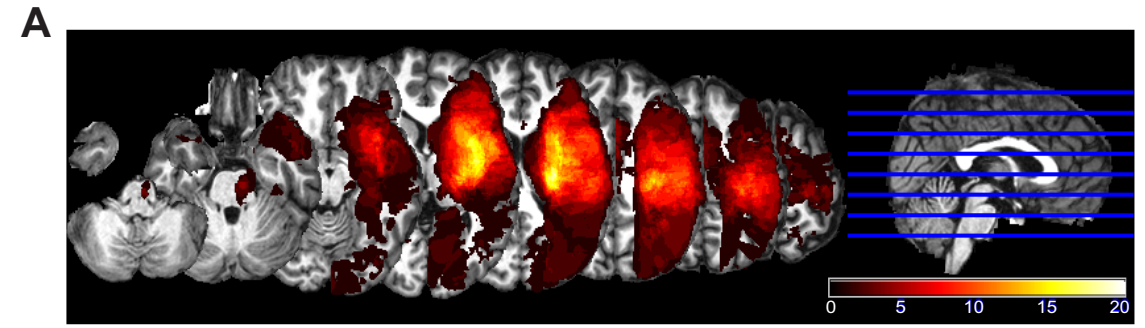

B

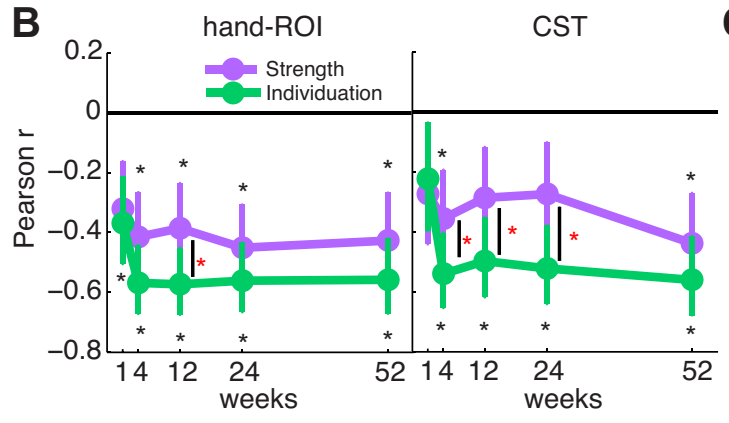

C

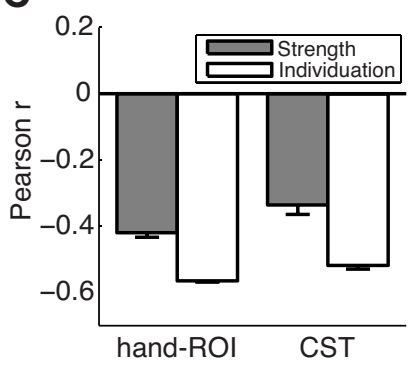


bioRxiv preprint doi: https://doi.org/10.1101/079269; this version posted October 7, 2016. The copyright holder for this preprint (which was not certified by peer review) is the author/funder, who has granted bioRxiv a license to display the preprint in perpetuity. It is made available under aCC-BY-NC-ND 4.0 International license.

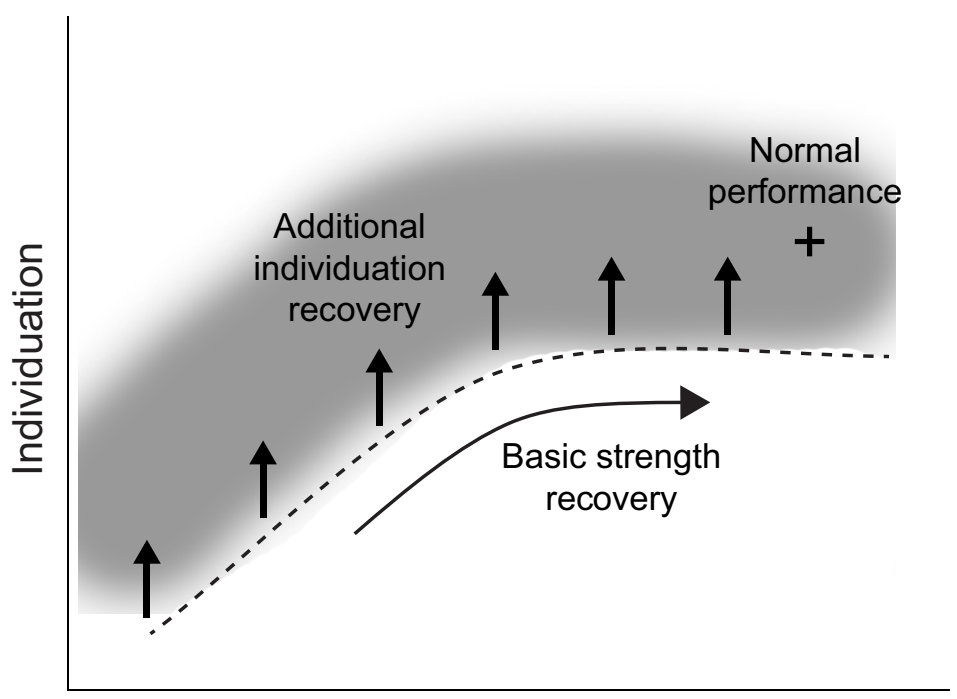

Strength 